\title{
Strong enhancement of chlorophyll a concentration by a weak typhoon
}

\author{
Liang Sun ${ }^{1,2, *}$, Yuan-Jian Yang ${ }^{3}$, Tao Xian ${ }^{1}$, Zhu-min Lu ${ }^{4}$, Yun-Fei Fu' \\ ${ }^{1}$ Laboratory of Atmospheric Observation and Climatological Environment, School of Earth and Space Sciences, \\ University of Science and Technology of China, Hefei, Anhui 230026, PR China \\ ${ }^{2}$ LASG, Institute of Atmospheric Physics, Chinese Academy of Sciences, Beijing 100029, PR China \\ ${ }^{3}$ Anhui Institute of Meteorological Sciences, Hefei 230031, PR China \\ ${ }^{4}$ Key Laboratory of Tropical Marine Environmental Dynamics, South China Sea Institute of Oceanology, Chinese Academy of \\ Sciences, Guangzhou 510301, PR China
}

\begin{abstract}
Recent studies demonstrate that chlorophyll a (chl a) concentrations in ocean surface waters can be significantly enhanced due to typhoons. The present study investigated chl a concentrations in the middle of the South China Sea (SCS) from 1997 to 2007 . Only the Category 1 (minimal) Typhoon Hagibis (2007) had a notable effect on chl a concentrations. Typhoon Hagibis had a strong upwelling potential due to its location near the equator, and the forcing time of the typhoon (>82 h) was much longer than the geostrophic adjustment time ( 63 h). The higher upwelling velocity and the longer forcing time increased the depth of the mixed-layer, which consequently induced a strong phytoplankton bloom that accounted for about $30 \%$ of the total annual chl a concentration in the middle of the SCS. Induction of significant upper ocean responses can be expected if the forcing time of a typhoon is long enough to establish strong upwelling.
\end{abstract}

KEY WORDS: SCS · Forcing time $\cdot$ Upwelling

Resale or republication not permitted without written consent of the publisher

\section{INTRODUCTION}

Investigations of the impacts of typhoons on the upper water levels of the ocean have determined that surface chlorophyll a (chl a) concentrations substantially increase after the passage of a typhoon (Subrahmanyam et al. 2002, Lin et al. 2003, McClain et al. 2004, Zheng \& Tang 2007, Gierach \& Subrahmanyam 2008, McClain 2009), especially in oligotrophic waters (Babin et al. 2004). The physical mechanism primarily responsible for the increase in chl a concentration is the typhoon's strong wind, which induces mixing and upwelling in the upper ocean (Price 1981) and brings both subsurface chl $a$ to the surface and subsurface nutrients into the euphotic zone (Subrahmanyam et al. 2002, Lin et al. 2003, Babin et al. 2004, Zheng \& Tang 2007, Gierach \& Subrahmanyam 2008). Although it is not clear whether the extra chl $a$ is due to the upwelling of nutrients or of $\operatorname{chl} a$, we are sure that both the typhoon-induced upwelling and the pre-existing eddies favor the enhancement of chl a (Walker et al. 2005, Shi \& Wang 2007, Zheng et al. 2008, McClain 2009, Sun et al. 2009). The stronger the upwelling is, the more nutrients are transported to the surface. However, whether typhoons have notable impacts on ocean primary production is a question still open to discussion.

On the one hand, single case studies, in which the impacts of super typhoons have been considered, showed that typhoons do have notable impacts on regional ocean primary production. In the East China Sea, Typhoon Meari induced a 3-fold increase in primary production, contributing $3.8 \%$ of the annual new production (Siswanto et al. 2008). For the South China Sea (SCS), it was also estimated that, on average, 30fold increases in surface chl a concentrations were triggered by Typhoons Kai-Tak (2000) (Lin et al. 2003) and Lingling (2001) (Shang et al. 2008). Typhoon Kai-Tak 
(2000) alone and typhoons occurring during the entire year induced from about 2 to $4 \%$ and 20 to $30 \%$ of the SCS's annual new primary production, respectively (Lin et al. 2003).

On the other hand, the integrated impact of tropical cyclones on sea surface chl a contradicts the abovementioned observations (Hanshaw et al. 2008, Zhao et al. 2008). A comparative study of Typhoons Lingling (2001) and Kai-Tak (2005) indicated that most of the typhoons in the SCS were relatively weak compared to Kai-Tak and Lingling and that typhoons accounted for $3.5 \%$ of the annual primary production in the oligotrophic SCS (Zhao et al. 2008). A similar conclusion was drawn for the North Atlantic; there the chl a concentration contributed to only $1.1 \%$ of the positive chl a anomaly within the hurricane season, which implies that an integrated impact of tropical cyclones may justifiably be ignored (Hanshaw et al. 2008). Such conclusions are not surprising if we recall the investigation of the hurricane-induced phytoplankton blooms in the Sargasso Sea (Babin et al. 2004); here it was found that 13 hurricanes induced, on average, a 3-fold (range from 1- to 9-fold) chl a increase for about $2 \mathrm{wk}$. Thus, each hurricane induced $<1 \%$ of the chl $a$ increase above the annual mean. Considering that about 3 to 4 hurricanes occur annually, the integrated impact of tropical cyclones on the chl a increase is very small, which is consistent with integrated estimations (Hanshaw et al. 2008, Zhao et al. 2008).

As the typhoon-induced chl a enhancement depends on the amount of subsurface nutrients transported into surface waters due to upwelling, the main question to be answered is whether a typhoon induces sufficiently strong upwelling. Motivated by such investigations and the above-mentioned arguments, the present study investigated the chl a concentrations in the SCS from 1997 to 2007 and found that only the Category 1 Typhoon Hagibis (2007) had a notable impact on the chl a concentration.

\section{MATERIALS AND METHODS}

The merged daily and monthly chl a concentration data (Level 3), with a spatial resolution of $9 \mathrm{~km}$ from 2 ocean color sensors (MODIS and SeaWiFS), were produced and distributed by the NASA Goddard Space Flight Center's Ocean Data Processing System (ODPS).

Typhoon tracking data, taken every $6 \mathrm{~h}$, including center location, central pressure and maximum $10 \mathrm{~min}$ mean sustained wind speeds (MSW), were obtained from the Shanghai Typhoon Institute (STI) of the China Meteorological Administration (CMA). In addition, 2 other types of wind data were used. One was the sea surface wind (SSW) vector and stress, with a spatial resolution of $1 / 4^{\circ} \times 1 / 4^{\circ}$, obtained from the daily QuikSCAT (Quick Scatterometer), provided by Remote Sensing Systems (www.remss.com/). Wind stress $\vec{\tau}$ was calculated with the bulk formula (Garratt 1977) such that:

$$
\vec{\tau}=\rho_{\mathrm{a}} C_{\mathrm{D}}|\vec{U}| \vec{U}
$$

where $\rho_{\mathrm{a}}$ and $\vec{U}$ are the air density and wind vector and $C_{D}=(0.73+0.069 U) \times 10^{-3}$ is the drag coefficient. According to recent studies (Powell et al. 2003, Jarosz et al. 2007), the above-mentioned drag coefficient is an overestimation for wind speeds $>40 \mathrm{~m} \mathrm{~s}^{-1}$. The potential upwelling velocity $V_{\mathrm{e}}$ due to wind was calculated using the Ekman pumping velocity (EPV) formula (Price et al. 1994):

$$
V_{\mathrm{e}}=\operatorname{curl}\left(\frac{\vec{\tau}}{\rho f}\right)
$$

where $\rho=1020 \mathrm{~kg} \mathrm{~m}^{-3}$ is the density of seawater and $f$ is the Coriolis parameter. The thermocline displacement (or isopycnal displacement) $\Delta_{\eta}$ due to a typhoon with translation speed $U_{T}$ was estimated according to Price et al. (1994) such that:

$$
\Delta_{\eta}=\frac{\vec{\tau}}{\rho f U_{T}}
$$

The second type of wind data used was the 'besttrack dataset' for the western North Pacific, obtained from the Joint Typhoon Warning Center (JTWC). Each best-track file contains locations and intensities of tropical cyclone centers (i.e. the maximum 1 min mean sustained $10 \mathrm{~m}$ wind speed), at $6 \mathrm{~h}$ intervals. Such maximum wind speeds can be found in Table 1 . These $1 \mathrm{~min}$ mean sustained wind speeds are relatively large compared with 10 min mean sustained wind speeds, which, according to recent studies (Powell et al. 2003, Jarosz et al. 2007), leads to even greater uncertainty in the calculation of wind stress. Thus, we used the MSW and a more modern drag law, i.e. $C_{D}=(-2.229+0.2983 U-$ $\left.0.00468 U^{2}\right) \times 10^{-3}$ (Jarosz et al. 2007), to calculate wind stress $\vec{\tau}$. In addition, wind with a fixed radius of $200 \mathrm{~km}$ and radii of specified winds $(35,50,65$, or 100 knots) for 4 quadrants were also considered; these data are useful for wind stress curl calculations. Finally, both wind stress $\vec{\tau}$ and wind diameter $D$ were used to perform EPV calculations for comparison such that:

$$
V_{\mathrm{e}}=\frac{\vec{\tau}}{\rho f D}
$$

For more details on the calculations of EPV and thermocline displacement see the 'Discussion' section.

On the other hand, in the present study, we also considered the forcing time of typhoons (Table 1), i.e. the typhoons' maximum wind blowing time $T_{\mathrm{b}}$ in the region (see Appendix 1 for details). The adjustment 
Table 1. Typhoons passing over the study area; data and calculations from the present study. MWS/BWS: maximum wind speed/ best-track wind speed; CT: category of typhoon; MS: translation speed; EPV: Ekman pumping velocity $V_{\mathrm{e}}$ AT: adjustment time $T_{\mathrm{a}}$; FT: forcing time $T_{b}$, superscripts ' $a$ ' and ' $b$ ': the values calculated according to Eq. (2) and Eq. (4), respectively; NA: not available

\begin{tabular}{|c|c|c|c|c|c|c|c|}
\hline $\begin{array}{l}\text { Typhoon } \\
\text { (name \& date) }\end{array}$ & $\begin{array}{l}\text { Latitude } \\
\left({ }^{\circ} \mathrm{N}\right)\end{array}$ & $\begin{array}{c}\text { MWS/BWS } \\
\left(\mathrm{m} \mathrm{s}^{-1}\right)\end{array}$ & $\mathrm{CT}$ & $\begin{array}{c}\mathrm{MS} \\
\left(\mathrm{m} \mathrm{s}^{-1}\right)\end{array}$ & $\begin{array}{l}\text { Max. EPV } \\
\left(10^{-4} \mathrm{~m} \mathrm{~s}^{-1}\right)\end{array}$ & $\begin{array}{l}\text { AT } \\
\text { (h) }\end{array}$ & $\begin{array}{l}\text { FT } \\
\text { (h) }\end{array}$ \\
\hline Faith (Dec 1998) & $10-12$ & $30 / 46.2$ & 2 & 4.3 & $\mathrm{NA}^{\mathrm{a}} / \mathrm{NA}^{\mathrm{b}}$ & 63 & NA \\
\hline Lingling (Nov 2001) & 13 & $50 / 59$ & 4 & 4.6 & $45.2^{\mathrm{a}} / 21.6^{\mathrm{b}}$ & 53 & 40 \\
\hline Nepartak (Nov 2003) & $13-15$ & $30 / 38.5$ & 1 & 4.6 & $7.8^{\mathrm{a}} / 17.8^{\mathrm{b}}$ & 50 & 20 \\
\hline Muifa (Nov 2004) & $9-12$ & $30 / 46.2$ & 2 & 3.1 & $10.7^{\mathrm{a}} / \mathrm{NA}^{\mathrm{b}}$ & 69 & 26 \\
\hline Chathu (Jun 2004) & $12-14$ & $33 / 38.5$ & 1 & 6.6 & $12.9^{\mathrm{a}} / \mathrm{NA}^{\mathrm{b}}$ & 53 & 15 \\
\hline Kai-tak (Oct 2005) & $12-15$ & $40 / 43.6$ & 2 & 2.2 & $15.7^{\mathrm{a}} / 17.9^{\mathrm{b}}$ & 53 & 52 \\
\hline Chanchu (May 2006) & $14-15$ & $50 / 64$ & 4 & 2.0 & $21.5^{\mathrm{a}} / 32.9^{\mathrm{b}}$ & 50 & 44 \\
\hline Chebi (Nov 2006) & 15 & $30 / 36$ & 1 & 4.1 & $2.9^{\mathrm{a}} / 16.8^{\mathrm{b}}$ & 45 & 16 \\
\hline Durian (Dec 2006) & $11-14$ & $40 / 46.2$ & 2 & 4.2 & $38.7^{\mathrm{a}} / 19.6^{\mathrm{b}}$ & 53 & 26 \\
\hline Utor (Dec 2006) & $14-15$ & $45 / 41$ & 1 & 4.5 & $14.8^{\mathrm{a}} / 26.1^{\mathrm{b}}$ & 50 & 18 \\
\hline Hagibis (Nov 2007) & $10-12$ & $35 / 41$ & 1 & 2.5 & $48.1^{\mathrm{a}} / 34.6^{\mathrm{b}}$ & 63 & 82 \\
\hline
\end{tabular}

times were also calculated for the typhoons passing the study area (Table 1); these were estimated by assuming that the upwelling is weak at the beginning of wind forcing and that the potential upwelling velocity is only reached after a period of time sufficient to allow the geostrophic adjustment process. According to geostrophic adjustment theory (Gill 1982), the adjustment time $T_{\mathrm{a}}$ required to become well established is at least $T_{\mathrm{a}}=1 / \mathrm{f}$.

The altimeter data were derived from multi-sensors (e.g. Jason-1, TOPEX/POSEIDON, GFO [Geosat Follow-On], ERS-2 and Envisat). Data were produced and distributed by AVSIO (Archiving, Validation and Interpretation of Satellite Oceanographic Data). Near-realtime-merged (TOPEX/POSEIDON or Jason-1 + ERS-
$1 / 2$, or Envisat) sea surface height anomaly (SSHA) data, which are high resolutions of the $1 / 4^{\circ} \times 1 / 4^{\circ}$ Mercator grid, are available at www.aviso.oceanobs.com. The geostrophic currents, derived from SSHA data with a resolution of $1 / 4^{\circ} \times 1 / 4^{\circ}$, are also available at www.aviso.oceanobs.com.

\section{RESULTS}

\section{Impact of Hagibis on chl a concentration}

Hagibis (2007) was a very weak typhoon and had a very special track (Fig. 1a). It was generated from a tropical depression east of the Philippines on Novem-
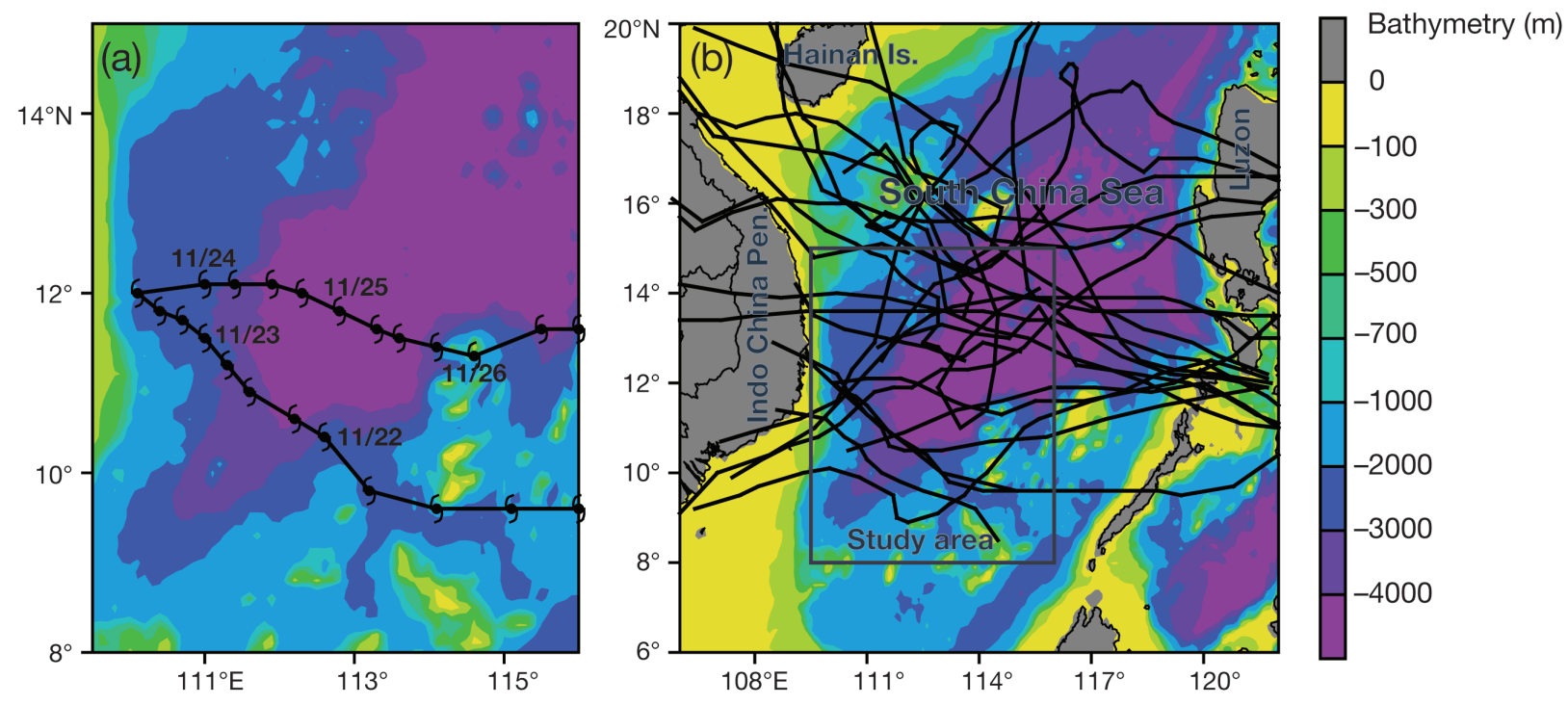

Fig. 1. (a) Track of Typhoon Hagibis (2007) in the study area; center positions for every $6 \mathrm{~h}$ are indicated. (b) Typhoon tracks in the South China Sea from 1997 to 2007 
ber 19, 2007 and was upgraded to a tropical storm soon after. On November 21, the storm was given typhoon status (central pressure of 963 mbar and maximum wind speed of $41 \mathrm{~m} \mathrm{~s}^{-1}$ ) and named Hagibis. This Category 1 typhoon moved slowly through the SCS, with a horizontal ' $\mathrm{V}$ '-type track. It passed through the middle of the SCS twice and remained in the area for $>5 \mathrm{~d}$.

Although Hagibis (2007) was very weak, it immediately had a great impact on the sea surface temperature (SST). Before the typhoon passed, the middle of the SCS was characterized by warm water (SST > $26^{\circ} \mathrm{C}$ ) (Fig. 2a). After the typhoon's passage, the strong winds caused by Hagibis (2007) led to a cooling of the sea surface in a wide area, with a maximum decrease of $7^{\circ} \mathrm{C}$ compared to the former temperatures along the typhoon's track (Fig. 2b). This maximum value of sea surface cooling, which was registered on November
25 , lagged about 3 d behind the typhoon's passage. It should be noted that the lower temperatures lasted for about 3 wk (Fig. 2c,d), much longer than the period of reduced temperatures observed in previous studies (Gierach \& Subrahmanyam 2008, Zhao et al. 2008).

Meanwhile, the sea surface chl a concentration was significantly enhanced during this period. Pre-typhoon chl a concentrations were from 0.1 to $0.2 \mathrm{mg} \mathrm{m}^{-3}$ in the SCS (Fig. 3a), but post-typhoon chl a concentrations increased to as high as $5.0 \mathrm{mg} \mathrm{m}^{-3}$ (increasing $>20$-fold) in some places during the period from November 11 to 30 (Fig. 3b). This strong enhancement of the chl a concentration lasted for $>3 \mathrm{wk}$, and the chl a concentrations were still very high $\left(>3.0 \mathrm{mg} \mathrm{m}^{-3}\right.$ ) from December 1 to 15 (Fig. 3c). The chl a concentration patterns (Fig. 3b,c) coincided well with those of the SST fields (Fig. 2b,c). Furthermore, this chl a
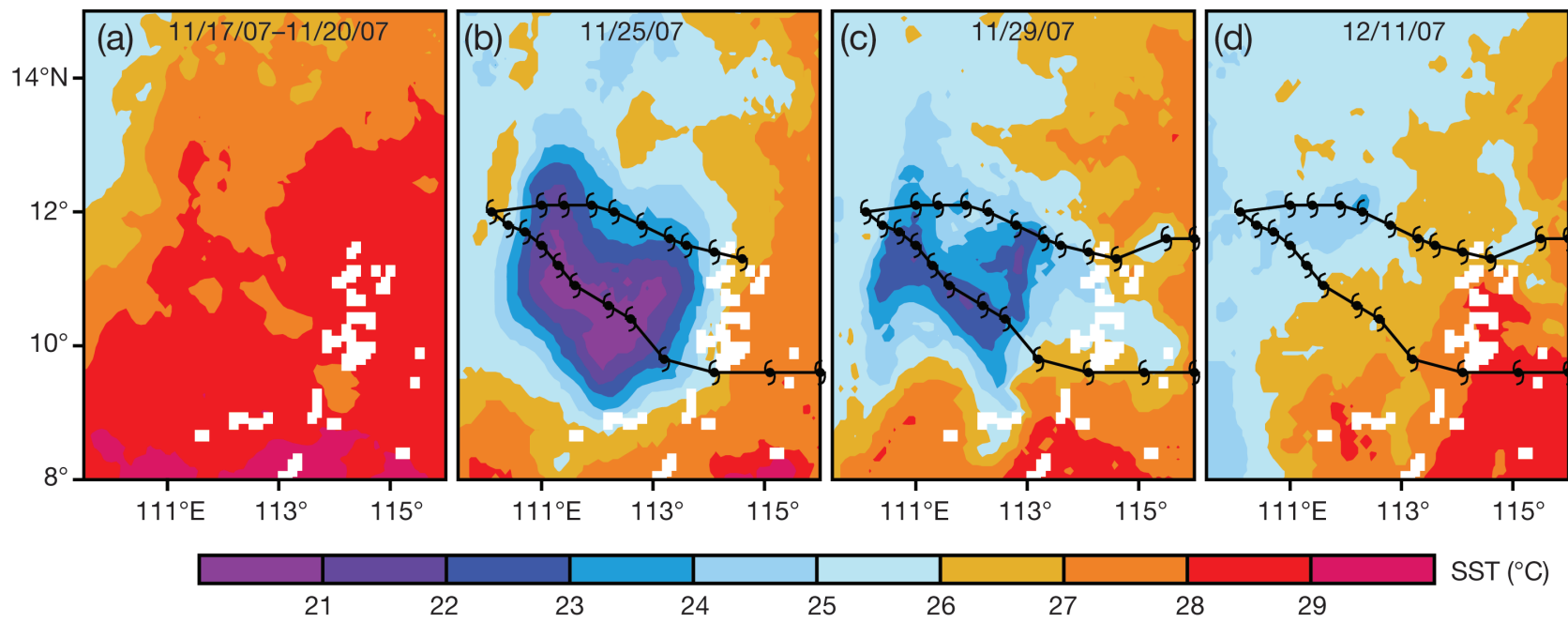

Fig. 2. Cooling of the sea surface temperature during the typhoon's passage, with a maximum decrease in temperature of $7^{\circ} \mathrm{C}$ after passage along the same track. Dates are $\mathrm{mm} / \mathrm{dd} / \mathrm{yy}$

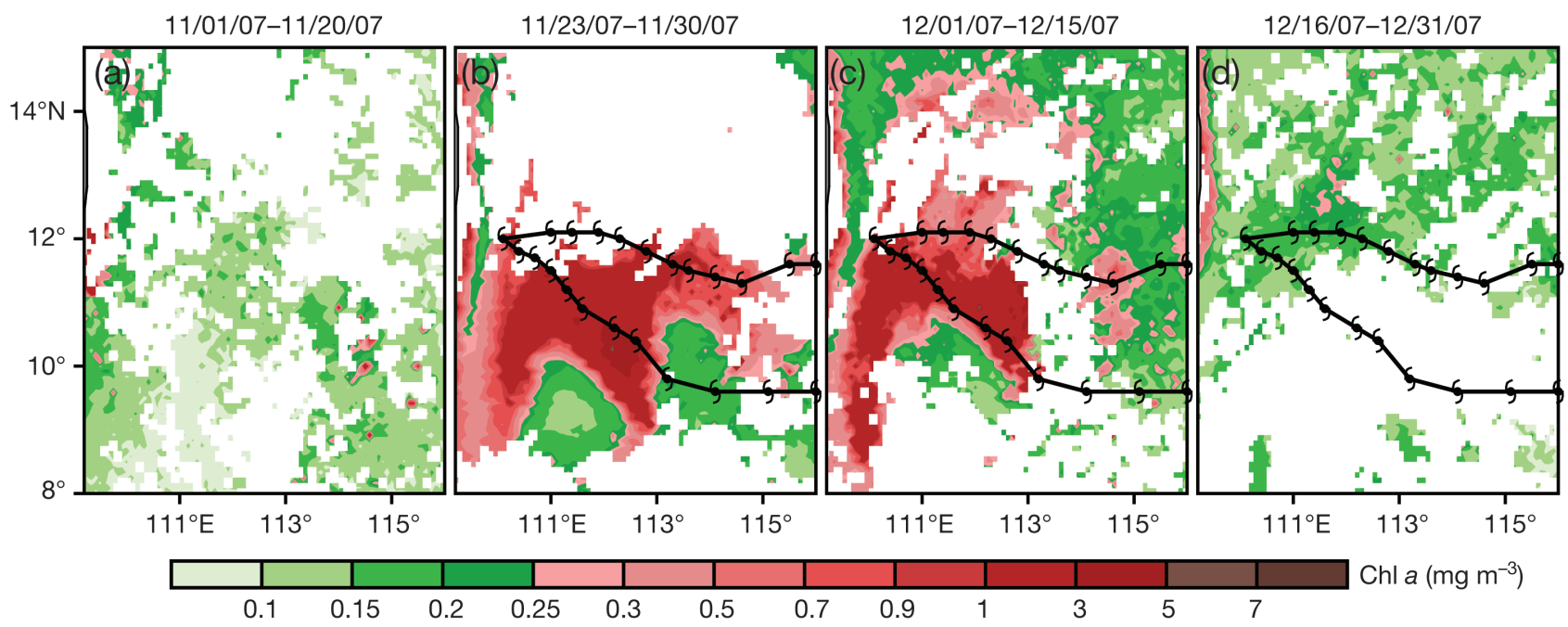

Fig. 3. Strong incidents of chlorophyll a enhancement (lasting $>3 \mathrm{wk}$ ) during the typhoon's passage. Dates are mm/dd/yy 
enhancement appeared to be due to local processes (vertical mixing, entrainment, or upwelling) rather than non-local processes (e.g. horizontal convection from the coastal region; Zhao \& Tang 2007), because there was a band of low chl a concentration separating the areas of high concentration offshore and along the coast. Finally, the bloom contributing the chl a died out a month after the typhoon passed (Fig. 3d).

To show the extent of the impact of Typhoon Hagibis, the distributions of chl a concentrations in the study area (according to the number of pixels) are shown in Fig. 4a, including both the pre-typhoon and post-typhoon situations. The peaks in chl a concentration were found at $0.11 \mathrm{mg} \mathrm{m}^{-3}$ before the typhoon) and at $0.21 \mathrm{mg} \mathrm{m}^{-3}$ after the typhoon. Furthermore, significantly higher pixel values $\left(>1.0 \mathrm{mg} \mathrm{m}^{-3}\right)$ occurred, in general, after the typhoon's passage. The area averages of chl a concentrations are depicted in Fig. $4 b_{\text {; }}$ the pre-typhoon and post-typhoon chl $a$ concentrations were 0.14 and $0.74 \mathrm{mg}$ $\mathrm{m}^{-3}$, respectively. Hagibis (2007) had a great impact on the chl a concentration in the middle of the SCS for about $1 \mathrm{mo}$. It is clear that the long-term blooming of phytoplankton was not due to upwelling of chl a but was instead due to upwelling of nutrients (Walker et al. 2005).

\section{Contribution to the climatological distribution in the middle of the SCS}

The above-mentioned enhancement of chl a concentration was so distinctive that it also contributed to the climatological distribution in the middle of the SCS. To illustrate this, the mean chl a values over $10 \mathrm{yr}$ (September 1997 to September 2007) in the SCS are depicted in Fig. 5. Chl a concentrations were higher in coastal and near-island regions than offshore. Chl a concentrations also had notable seasonal variations. In the summer, there was a high chl a concentration off Vietnam
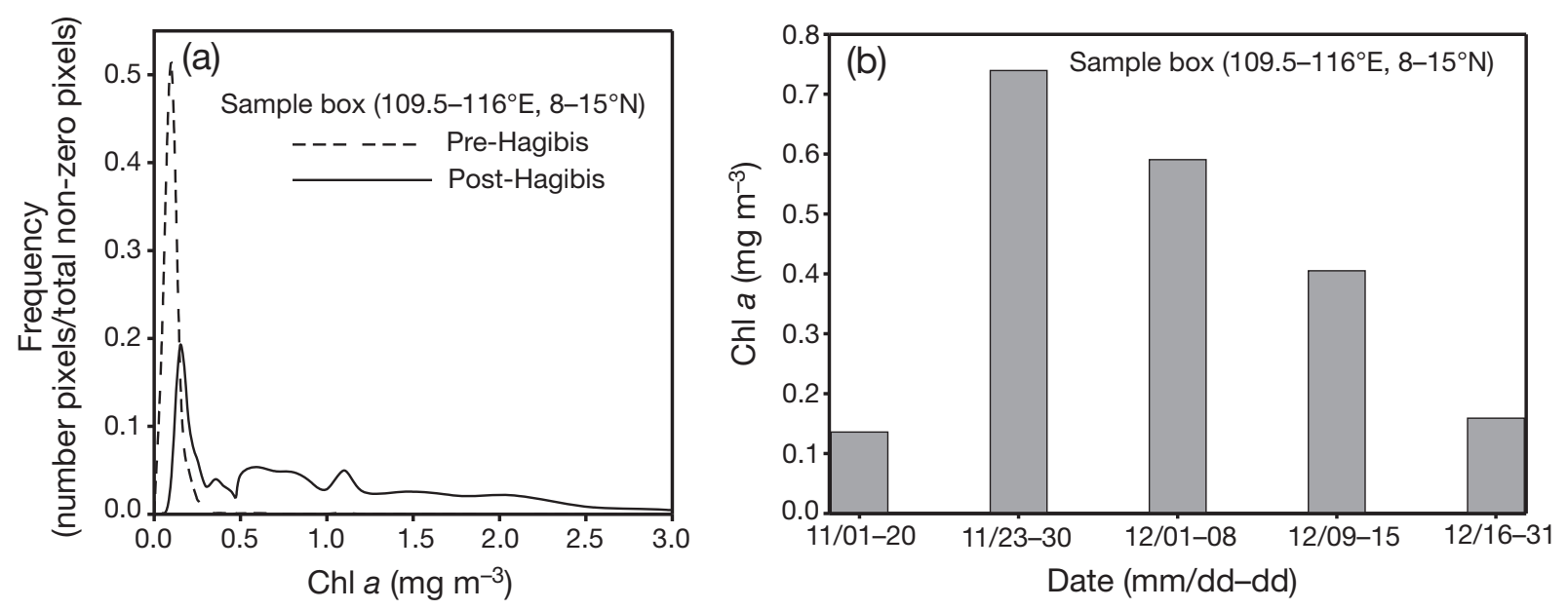

Fig. 4. (a) Distributions of chlorophyll a ( $\mathrm{chl}$ a) by the number of pixels, for the pre- (dashed) and post- (solid) typhoon situations. (b) Time series of area averages of chl $a$, when typhoon-induced blooming lasted for $>3 \mathrm{wk}$

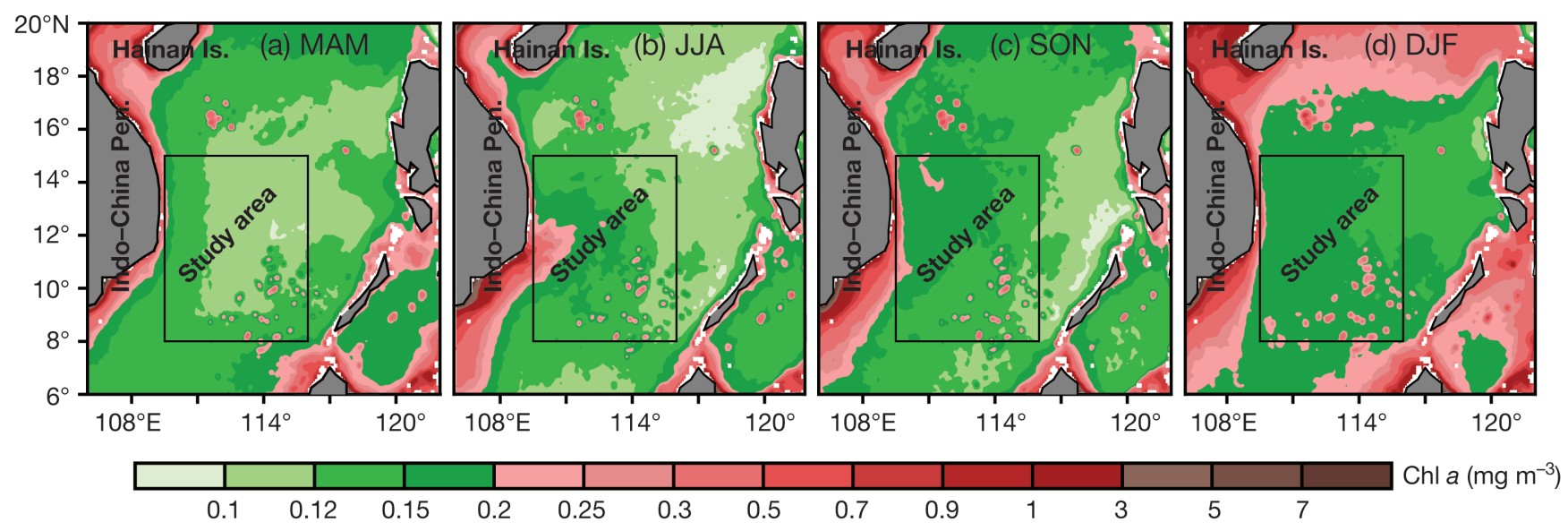

Fig. 5. Seasonal means of chlorophyll a concentrations in the South China Sea. The chl a concentration is higher in coastal and near-island regions than offshore 
(Fig. 5b), because southwest-northeast monsoon winds are roughly parallel to the coastline southeast of Vietnam and favorable wind-direction and strong winds can lead to coastal upwelling in coastal areas and Ekman upwelling in offshore areas (Zhao \& Tang 2007).

The impact of Hagibis on the chl a concentration in the middle of the SCS (the box in Fig. 1) can be seen in Fig. 6 . In Fig. 6a, the monthly means of chl a concentrations in the middle of the SCS during the $10 \mathrm{yr}$ period (September 1997 to September 2007) are depicted. Prior to 2007, the chl a concentration exhibited fairly constant seasonal variations: the concentrations were lowest in May $\left(0.1 \mathrm{mg} \mathrm{m}^{-3}\right)$ and highest in August $\left(0.25 \mathrm{mg} \mathrm{m}^{-3}\right.$; Fig. 6$)$. In addition, the annual chl a concentration was about $1.78 \mathrm{mg} \mathrm{m}^{-3}$, by integration of the monthly means in the region. However, the chl a concentrations in November and December of 2007 (0.467 and $0.416 \mathrm{mg} \mathrm{m}^{-3}$ ), after Typhoon Hagibis (2007) passed over the SCS, were significantly higher than before (Fig. 6b). Thus, the monthly means of chl a concentrations in these 2 mo increased notably from 0.157 and 0.184 to 0.188 and $0.207 \mathrm{mg} \mathrm{m}^{-3}$, respectively, due to the anomaly (Fig. 6a). We estimated that the Typhoon Hagibis-induced chl $a$ increase was $0.55 \mathrm{mg} \mathrm{m}^{-3}$ in 2 mo by subtracting the average chl $a$ $\left(0.157+0.184=0.341 \mathrm{mg} \mathrm{m}^{-3}\right.$ in $\left.2 \mathrm{mo}\right)$ from the post typhoon chl a $\left(0.467+0.416=0.883 \mathrm{mg} \mathrm{m}^{-3}\right.$ in $\left.2 \mathrm{mo}\right)$ which accounted for about $30 \%$ of the annual chl a concentration $\left(1.78 \mathrm{mg} \mathrm{m}^{-3}\right)$ and for about $2.8 \%$ of the total $\mathrm{chl} a$ concentration $\left(19.6 \mathrm{mg} \mathrm{m}^{-3}\right)$ in the middle of the SCS.

\section{Physical mechanism}

As mentioned above, Typhoon Hagibis (2007) had a great impact on the chl a concentration in the middle of the SCS. The SCS is not only a region of typhoon passage, but it is also an area of significant tropical cyclone genesis (Wang et al. 2007). It was found that 28 tropical storms passed through the middle of the SCS during the period from 1997 to 2007 (Fig. 1b); 11 of them were typhoon status storms (Table 1). However, other typhoons, even though much stronger, had little impact on the chl a enhancement in the middle of the SCS. Thus, the strong local upwelling and thermocline displacement induced by Typhoon Hagibis (2007) appear to have led to the surface phytoplankton blooms, which, in turn, enhanced the chl a concentration.

To further explore this line of enquiry, we first considered the potential of typhoon-induced Ekman pumping. Fig. 7 depicts the potential EPV fields derived from the wind fields during Typhoon Hagibis's passage. The EPV maximum values were from ca. $30 \times 10^{-4}$ to $50 \times$ $10^{-4} \mathrm{~m} \mathrm{~s}^{-1}$ on the evening of November 21 (Fig. 7a) and from ca. $50 \times 10^{-4}$ to $60 \times 10^{-4} \mathrm{~m} \mathrm{~s}^{-1}$ on the night of November 22 (Fig. 7b), after which Hagibis crept westward to the coastline southeast of Vietnam. Comparing the present results with those of previous studies (Lin et al. 2003, Shi \& Wang 2007, Gierach \& Subrahmanyam 2008, Shang et al. 2008), we determined that the EPV was quite large in the case of Typhoon Hagibis (Table 2); this large value probably reflected the fact that Hagibis passed close to the equator (at $\left.10^{\circ} \mathrm{N}\right)$, and the Coriolis parameter was about half that of other typhoons, which were tracked at approximately $20^{\circ} \mathrm{N}$. Thus, the potential EPV calculated from Eq. (1) should be twice as large as that due to a typhoon with the same strength at a higher latitude.

In addtion, the longer forcing time of Hagibis (2007) played an important role in the establishment of the potential EPV. According to geostrophic adjustment theory, such an upwelling process requires a geostrophic adjustment time of at least $T_{\mathrm{a}}=1 / f$ to be
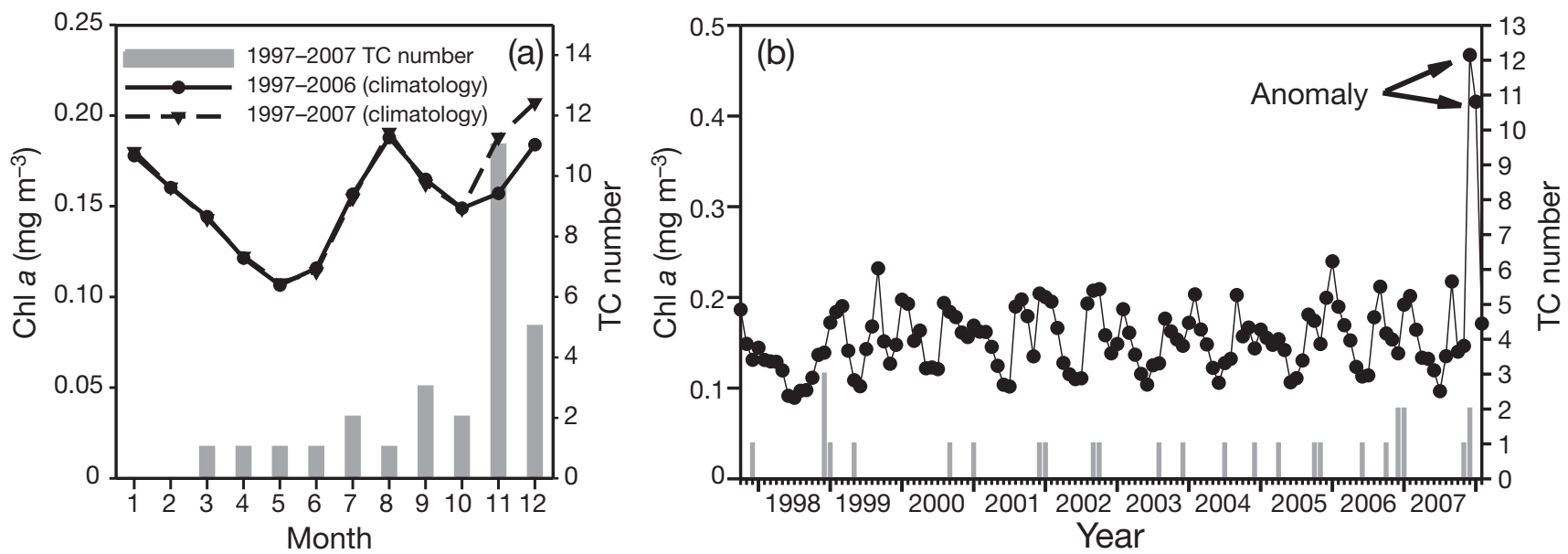

Fig. 6. (a) Monthly means of chlorophyll a, pre- (dashed) and post- (solid) typhoon, and the number of tropical cyclones (TC) that passed over the study area. (b) Time series of average chlorophyll a (chl a) concentrations and tropical cyclones. The impact of Hagibis (2007) on the chl a concentration is labeled 'Anomaly' 


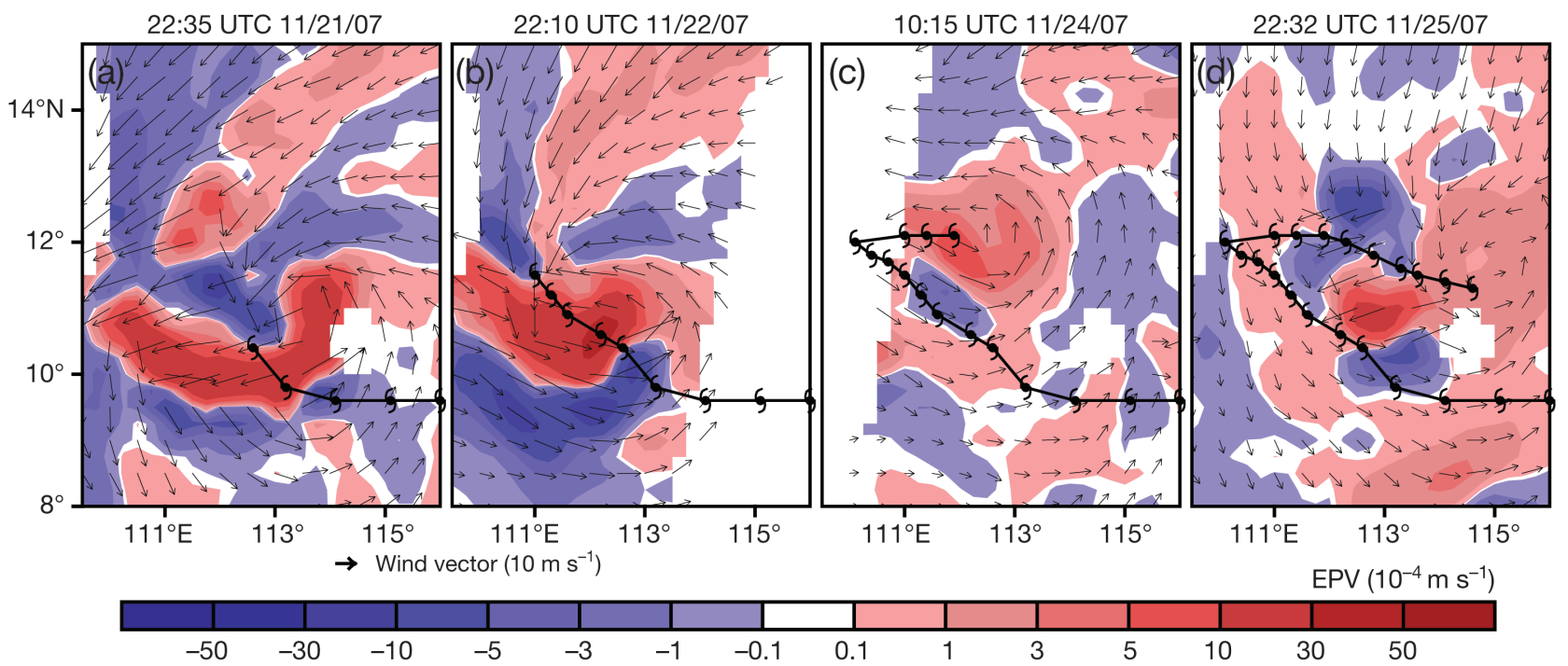

Fig. 7. Ekman pumping velocity (EPV; color key) during the passage of Typhoon Hagibis. The maximum EPV (ca. $50 \times 10^{-4}$ to $60 \times 10^{-4} \mathrm{~m} \mathrm{~s}^{-1}$ ) was quite large during this period. Dates are $\mathrm{mm} / \mathrm{dd} / \mathrm{yy}$

well established. If the typhoon's forcing time is not long enough, the upwelling velocity would be much lower than the maximum potential EPV. In Table 1, both the forcing time and the adjustment time for the typhoons considered are given. For most of the typhoons, the forcing time was significantly shorter than the adjustment time, especially for fast-moving typhoons; thus, the potential EPV could not be achieved for the upwelling velocity. Because Typhoon Hagibis had a much longer forcing time ( $>82 \mathrm{~h})$ than the minimal time required $(\sim 63 \mathrm{~h})$, the maximum potential EPV was nearly reached. The large upwelling velocity and long forcing time of this typhoon led to strong thermocline displacement and, subsequently, to extreme biophysical responses.

Finally, the vertical mixing and upwelling caused by Hagibis also induced a cyclonic eddy as the sea surface height decreased immediately south of the typhoon track (Fig. 8a-d). Meanwhile, around the eddy, the mixed-layer was found to occur about $25 \mathrm{~m}$ deeper, based on the temperature profiles of Argo Float 5900059 (Fig. 8e). It is possible that the mixedlayer at the eddy center occurred even deeper. Comparing Fig. 8 with Fig. 7, the center of the cyclonic eddy coincides with the position of the SST cooling center, which implies that both phenomena were due to the same local mixing and upwelling processes. Such a cyclonic eddy also induces strong cyclonic flow. The enhanced cyclonic eddy induced a strong geostrophic current along the coast $\left(\sim 1.0 \mathrm{~m} \mathrm{~s}^{-1}\right)$; in comparison, before the typhoon, the surface flow was weak $\left(\sim 0.4 \mathrm{~m} \mathrm{~s}^{-1}\right)$. In the present study, we noted that the Argo float track ran parallel to the geostrophic current (Fig. 8a-d) and that the flow speed obtained from the SSHA data agreed well with the data obtained from Argo (Fig. 8f). Thus, the current

Table 2. Typhoons and their locations; results of previous studies. MWS: maximum wind speed; CT: category of typhoon; MS: translation speed; EPV: Ekman pumping velocity using Eq. (2) and QuikSCAT data; dMLD: difference of mixed layer depths; TD: thermocline displacement using Eq. (3) and QuikSCAT data; NA: not available

\begin{tabular}{|lccccccl|}
\hline $\begin{array}{l}\text { Typhoon } \\
\text { (name \& year) }\end{array}$ & $\begin{array}{c}\text { Latitude } \\
\left({ }^{\circ}\right)\end{array}$ & $\begin{array}{l}\text { MWS } \\
\left(\mathrm{m} \mathrm{s}^{-1}\right)\end{array}$ & CT & $\begin{array}{c}\text { MS } \\
\left(\mathrm{m} \mathrm{s}^{-1}\right)\end{array}$ & $\begin{array}{c}\text { Max. EPV } \\
\left(10^{-4} \mathrm{~m} \mathrm{~s}^{-1}\right)\end{array}$ & $\begin{array}{c}\text { dMLD/TD } \\
(\mathrm{m})\end{array}$ & Source \\
\hline Kai-Tak (2000) & 20 & 48 & 2 & 4.5 & 20 & $21 / 90$ & Lin et al. (2003) \\
Lingling (2001) & 14 & 59 & 4 & 5 & NA & $20 / 100$ & Shang et al. (200)8 \\
Hai-Tang (2005) & 25 & 70 & 5 & 11 & 0.7 & NA & Chang et al. (2008) \\
Kai-Tak (2005) & 13 & 46 & 2 & 2.9 & 1.7 & $23.5 / \mathrm{NA}$ & Zheng \& Tang (2007) \\
Katrinia (2005) & 24 & 77 & 5 & 3.4 & 20 & NA/80 & Shi \& Wang (2007) \\
Katrinia (2005) & 24 & 77 & 5 & 3.4 & 5 & NA/63 & Gierach \& Subrahmanyam (2008) \\
Rita (2005) & 27 & 80 & 5 & 4.5 & 12 & NA/87 & Gierach \& Subrahmanyam (2008) \\
Wilma (2005) & 21 & 82 & 5 & 3.6 & 7 & NA/45 & Gierach \& Subrahmanyam (2008) \\
Hagibis (2007) & 10 & 41 & 1 & 2.5 & 48.1 & $25 / 105$ & Present study \\
\hline
\end{tabular}



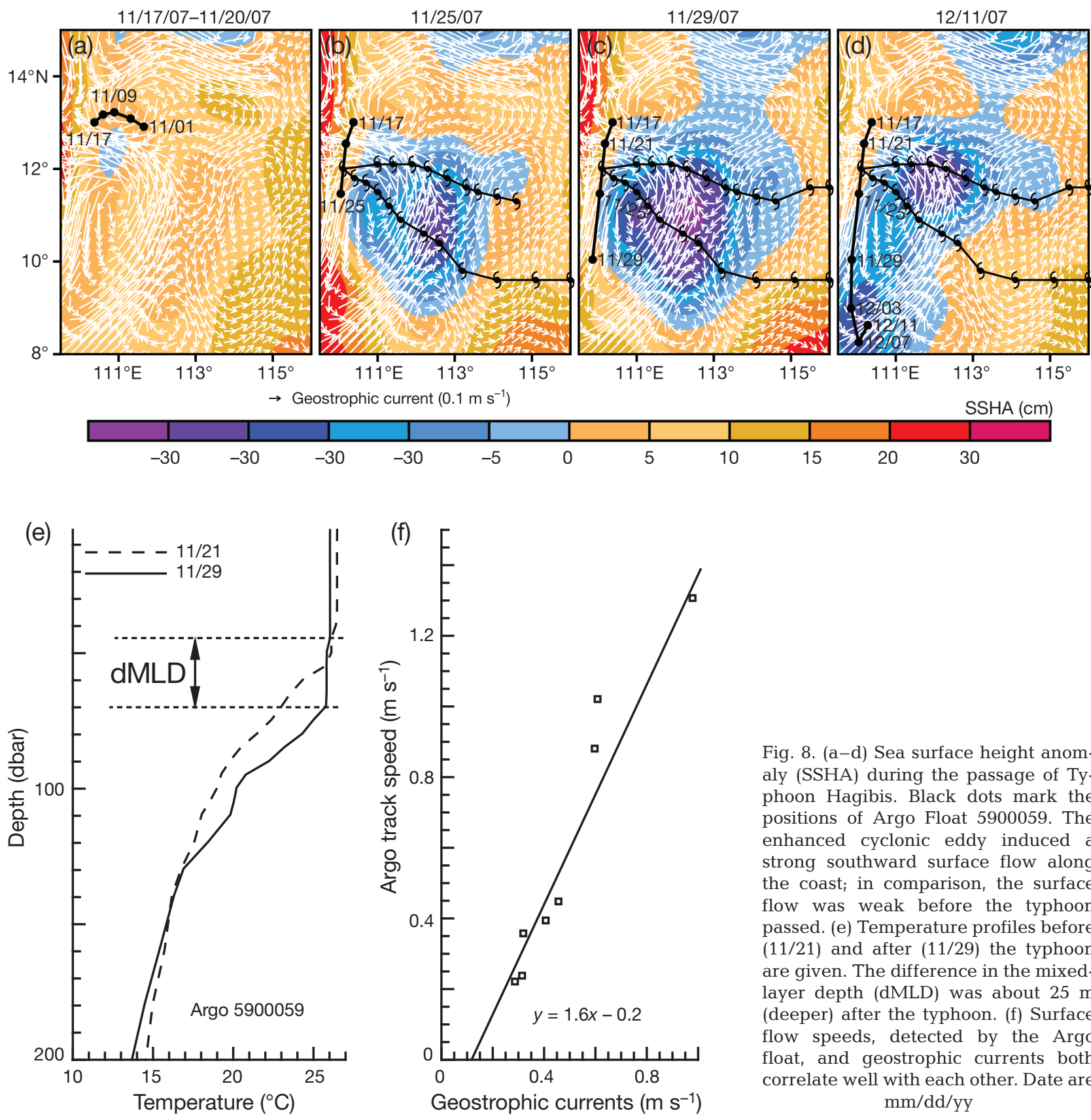

Fig. 8. (a-d) Sea surface height anomaly (SSHA) during the passage of Typhoon Hagibis. Black dots mark the positions of Argo Float 5900059. The enhanced cyclonic eddy induced a strong southward surface flow along the coast; in comparison, the surface flow was weak before the typhoon passed. (e) Temperature profiles before $(11 / 21)$ and after $(11 / 29)$ the typhoon are given. The difference in the mixedlayer depth (dMLD) was about $25 \mathrm{~m}$ (deeper) after the typhoon. (f) Surface flow speeds, detected by the Argo float, and geostrophic currents both correlate well with each other. Date are $\mathrm{mm} / \mathrm{dd} / \mathrm{yy}$

apparently brought the high chl a waters to the south along the eddy. High chl a concentration waters were initially located near the typhoon track (Fig. 3b), and were later transported along the coast to the south by surface flow (Fig. 3c). According to Eq. (3), the thermocline displacement was about $100 \mathrm{~m}$, which is quite a bit greater than that found in other cases (Table 2). The cyclonic eddy was not stable; it broke into 2 small eddies between November 29 and December 11: the larger of them moved northward, and the smaller one southward.

\section{DISCUSSION}

The present investigation shows that forcing time might be the most important factor stimulating ocean responses to typhoons. As shown in Table 1, 4 typhoons have forcing times $>40 \mathrm{~h}$, including Typhoon Hagibis (2007). Two of them, Lingling (2001) and Kai-Tak (2005), have previously been investigated (Zheng \& Tang 2007, Shang et al. 2008, Zhao et al. 2008). Both had notable impacts on the regional increase in chl a. Typhoon Chanchu (2006), not only 
had some temporarily (but in comparison to Typhoon Hagibis relatively small) impacts on the chl a concentration in the northern SCS (Fig. 9), but, in 2006, it also influenced the onset of the summer monsoon in the SCS (Mao and Wu 2008). Other typhoons, even if they were higher in intensity, had smaller impacts on ocean responses and have not yet been investigated.

Compared with forcing time, typhoon intensity appears to be less important. This may be associated with the reduced drag coefficient for high wind speeds in tropical cyclones (Powell et al. 2003, Jarosz et al. $2007)$; the wind stress at high wind speeds (>50 $\mathrm{m} \mathrm{s}^{-1}$ ) is only slightly greater than that at low wind speeds (ca. 30 to $40 \mathrm{~m} \mathrm{~s}^{-1}$ ).

Although pre-existing oceanic conditions (cold core eddies) also play minor roles in ocean responses, they were often important in this respect in the upper ocean (Walker et al. 2005, Shi \& Wang 2007, Zheng et al. 2008, Sun et al. 2009). In fact, in some cases, cyclonic eddies became major contributors to sea surface cooling (Zheng et al. 2008, Wada et al. 2009). One large, cold core eddy appeared to be generated by typhoon wind forcing (Fig. 8b), which might represent one of the cold eddy genesis mechanisms.

The advection of chl a from one place to another could also cause a temporary chl a concentration increase (Zhao \& Tang 2007, Yang et al. 2010). In the present study, the original chl a concentration enhancement took place beneath the typhoon track. Then, this chl a was advected southwards along the edge of the eddy for about $300 \mathrm{~km}$ (even to the left of the typhoon track). This implies that the impact of typhoons on surface chl a through advection could be more extensive than previously believed.

In the literature, as well as in the present investigation, EPV was calculated according to Eq. (2). We also used the 'best-track dataset', the new drag law (Jarosz et al. 2007) and Eq. (4) to calculate the EPV (Table 2). We found that the EPV induced by Typhoon Hagibis (2007) was still the largest, although the EPVs calculated by Eq. (4) were different from those calculated using Eq. (2).

Enhancement of the chl a concentration depends on the Ekman pumping of subsurface nutrients and, hence, on typhoon-induced wind stress and the forcing time. Thus, the physical formula is important for relating thermocline displacement in the upper ocean to a typhoon's parameters, e.g. a typhoon's intensity, wind stress and moving speed (Price 1981). For this purpose, thermocline displacement is estimated to be directly proportional to typhoon-induced surface wind stress and inversely proportional to the typhoon's moving speed (Price et al. 1994), as seen in Eq. (3), which can be understood according to the concept of translation time (Lin et al. 2008). Such a concept assumes that the typhoon-induced response is directly proportional to the typhoon's diameter $D$ and inversely proportional to the typhoon's moving speed $U_{T}$. Thus, thermocline displacement is estimated as the product of the potential EPV and translation time such that:

$$
\Delta_{\eta}=\frac{\operatorname{curl}(\vec{\tau})}{\rho f} \times \frac{D}{U_{T}} \simeq \frac{\vec{\tau} / D}{\rho f} \times \frac{D}{U_{T}}=\frac{\vec{\tau}}{\rho f U_{T}}
$$

which is exactly the same as Eq. (3).

However, such a formulation would overestimate the typhoon's forcing, as the forcing times of the typhoons in Table 1 are often not long enough to achieve the maximum potential EPV. For fast-moving typhoons, the wind-induced upwelling should be very weak and the thermocline displacement might be inversely proportional to the typhoon's moving speed squared. Nevertheless, further studies are needed to develop a more
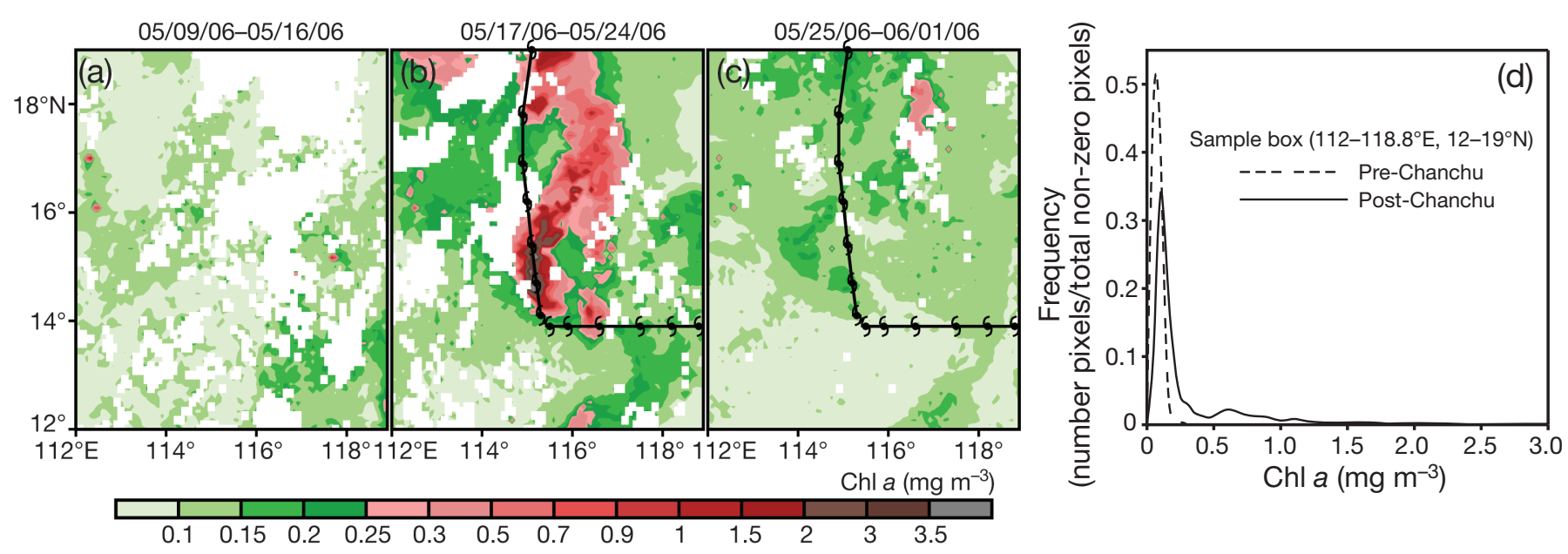

Fig. 9. Ocean surface chlorophyll a concentration in response to Typhoon Chanchu (2006) was observed, but weaker than the response to Typhoon Hagibis (2007). Dates are mm/dd/yy 
accurate method of estimation. The incorporation of in situ observations (Dickey et al. 1998, Zedler et al. 2002, Black \& Dickey 2008) would be very helpful in this effort.

Overall, Typhoon Hagibis (2007) had a great impact on the climatology and chl a concentration in the middle of the SCS, above all, because of the location of the typhoon's track and its long forcing time (Fig. 10). A strong upwelling trend was established, and advection was able to carry the extra chl a $300 \mathrm{~km}$ away from the typhoon's track. Compared to these mechanisms, the intensity of the typhoon, its wind speed and the upwelling of chl a played minor roles in this case.

\section{CONCLUSIONS}

In 2007, Typhoon Hagibis (Category 1) had the greatest impact on the chl a concentration in the SCS, although > 20 typhoons passed over the region. This slowly moving typhoon, with a horizontal ' $\mathrm{V}$ '-type track, stayed in the SCS for $>5 \mathrm{~d}$. The long forcing time (>82 h) due to the typhoon induced strong upwelling and caused a significant phytoplankton bloom that accounted for 30 and $2.8 \%$ of the annual and total chl a concentrations (1997 to 2007), respectively, in the middle of the SCS. Compared to these mechanisms, the intensity of the typhoon, the wind speed and the

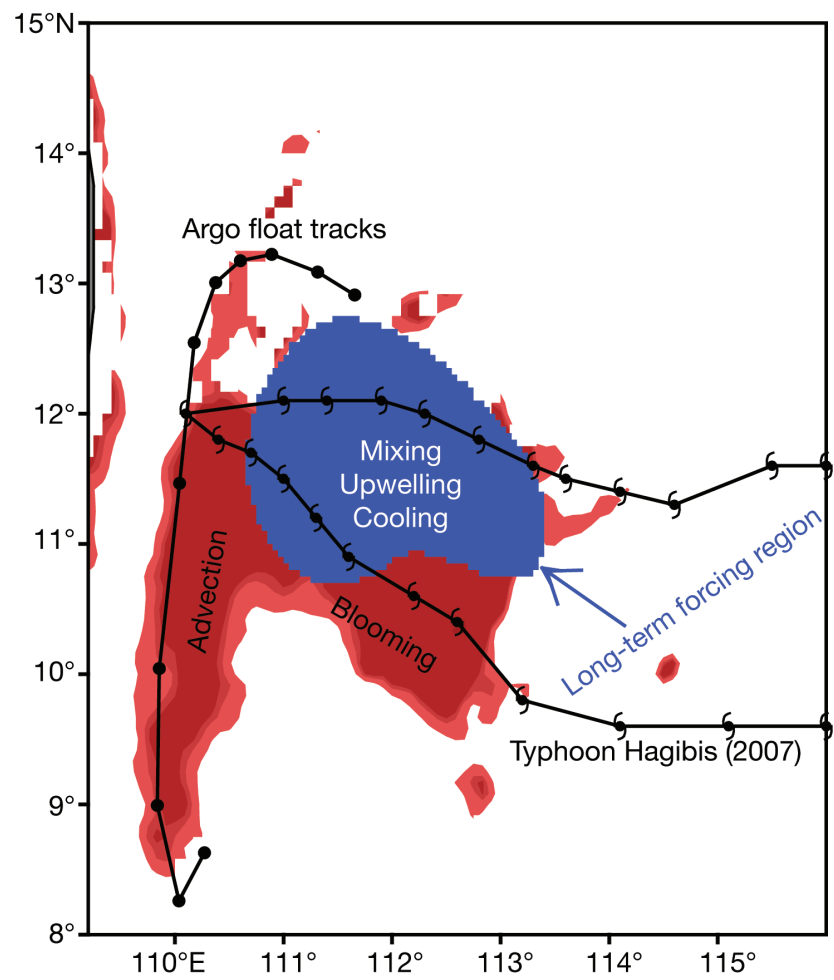

Fig. 10. Diagram of ocean responses to Typhoon Hagibis (2007) upwelling of chl a played minor roles in this case. It can also be argued that Price's formula overestimates typhoon-forced upwelling and that a more accurate formula is needed.

Acknowledgements. We thank 4 anonymous reviewers for their constructive suggestions. This work was supported by the National Basic Research Program of China (No. 2007CB816004), the Knowledge Innovation Program of the Chinese Academy of Sciences (Nos. KZCX2-YW-QN514 and KZCX2-YW-226), the National Foundation of Natural Science (Nos. 40705027 and 40730950) and the Open Fund of State Key Laboratory of Satellite Ocean Environment Dynamics (No. SOED0902). We thank Shanghai Typhoon Institute (STI) of China Meteorological Administration (CMA) for providing typhoon tracking data, China Argo Real-time Data Center for the Argo float profiles, NASA's Ocean Color Working Group for providing Modis and SeaWiFS data, AVISO for SSHA data and Remote Sensing Systems for TMI/AMSR-E SST data.

\section{LITERATURE CITED}

Babin SM, Carton JA, Dickey TD, Wiggert JD (2004) Satellite evidence of hurricane-induced phytoplankton blooms in an oceanic desert. J Geophys Res 109:C03043. doi:10. 1029/2003JC001938

Black WJ, Dickey TD (2008) Observations and analyses of upper ocean responses to tropical storms and hurricanes in the vicinity of Bermuda. J Geophys Res 113:C08009. doi:10.1029/2007JC004358

Chang Y, Liao HT, Lee MA, Chan JW and others (2008) Multisatellite observation on upwelling after the passage of Typhoon Hai-Tang in the southern East China Sea. Geophys Res Lett 35:L03612. doi:10.1029/2007GL032858

Dickey T, Frye D, McNeil J, Manov D and others (1998) Upper-ocean temperature response to Hurricane Felix as measured by the Bermuda Testbed Mooring. Mon Weather Rev 126:1195-1201

Garratt JR (1977) Review of drag coefficients over oceans and continents. Mon Weather Rev 105:915-929

Gierach MM, Subrahmanyam B (2008) Biophysical responses of the upper ocean to major Gulf of Mexico hurricanes in 2005. J Geophys Res 113:C04029. doi:10.1029/2007J $\mathrm{C} 004419$

Gill AE (1982) Atmosphere-Ocean dynamics. Academic Press, London

> Hanshaw MN, Lozier MS, Palter JB (2008) Integrated impact of tropical cyclones on sea surface chlorophyll in the North Atlantic. Geophys Res Lett 35:L01601. doi:10.1029/2007 GL031862

Jarosz E, Mitchell DA, Wang DW, Teague WJ (2007) Bottomup determination of air-sea momentum exchange under a major tropical cyclone. Science 315:1707-1709

Lin I, Liu WT, Wu CC, Wong GTF and others (2003) New evidence for enhanced ocean primary production triggered by tropical cyclone. Geophys Res Lett 30:1718. doi: 10.1029/2003GL017141

> Lin II, Wu CC, Pun IF, Ko DS (2008) Upper ocean thermal structure and the western North Pacific category-5 typhoons. Part I: ocean features and category-5 typhoon's intensification. Mon Weather Rev 136:3288-3306

Mao J, Wu G (2008) Influences of Typhoon Chanchu on the 2006 South China Sea summer monsoon onset. Geophys Res Lett 35:L12809. doi:10.1029/2008GL033810 
McClain CR (2009) A decade of satellite ocean color observations. Annu Rev Mar Sci 1:19-42

McClain CR, Signorini SR, Christian JR (2004) Subtropical gyre variability observed by ocean-color satellites. DeepSea Res II 51:281-301

Powell MD, Vickery PJ, Reinhold TA (2003) Reduced drag coefficient for high wind speeds in tropical cyclones. Nature 422:279-283

Price JF (1981) Upper ocean response to a hurricane. J Phys Oceanogr 11:153-175

Price JF, Sanford TB, Forristall GZ (1994) Forced stage response to a moving hurricane. J Phys Oceanogr 24: 233-260

Shang S, Li L, Sun F, Wu J and others (2008) Changes of temperature and bio-optical properties in the South China Sea in response to Typhoon Lingling, 2001. Geophys Res Lett 35:L10602. doi:10.1029/ 2008GL033502

> Shi W, Wang M (2007) Observations of a Hurricane Katrina-induced phytoplankton bloom in the Gulf of Mexico. Geophys Res Lett 34:L11607. doi:10.1029/2007 GL029724

Siswanto E, Ishizaka J, Morimoto A, Tanaka K, Okamura K, Kristijono A, Saino T (2008) Ocean physical and biogeochemical responses to the passage of Typhoon Meari in the East China Sea observed from Argo float and multiplatform satellites. Geophys Res Lett 35:L15604. doi:10.1029/2008GL035040

Subrahmanyam B, Rao KH, Rao SN, Murty VSN, Sharp RJ (2002) Influence of a tropical cyclone on chlorophyll-a concentration in the Arabian Sea. Geophys Res Lett 29:2065. doi:10.1029/2002GL015892

Sun L, Yang YJ, Fu YF (2009) Impacts of typhoons on the Kuroshio Large Meander: observation evidences. Atmos Ocean Sci Lett 2:40-45
Wada A, Sato K, Usui N, Kawai Y (2009) Comment on 'Importance of pre-existing oceanic conditions to upper ocean response induced by Super Typhoon Hai-Tang' by Z.-W. Zheng, C.-R. Ho, and N.-J. Kuo. Geophys Res Lett 36:L09603. doi:10.1029/2008GL036890

Walker ND, Leben RR, Balasubramanian S (2005) Hurricaneforced upwelling and chlorophyll a enhancement within cold-core cyclones in the Gulf of Mexico. Geophys Res Lett 32:L18610. doi:10.1029/2005GL023716

Wang GH, SU JL, Ding Y, Chen D (2007) Tropical cyclones genesis over the South China Sea. J Mar Syst 68(3-4): 318-326

Yang YJ, Sun L, Liu Q, Xian T, Fu YF (2010) The biophysical responses of the upper ocean to the typhoons Namtheun and Malou in 2004. Int J Remote Sens (in press)

Zedler SE, Dickey TD, Doney SC, Price JF, Yu X, Mellor GL (2002) Analyses and simulations of the upper ocean's response to Hurricane Felix at the Bermuda Test bed Mooring site: 13-23 August 1995. J Geophys Res 107(C12):3232. doi:10.1029/2001JC000969

Zhao H, Tang DL (2007) Effect of 1998 El Nino on the distribution of phytoplankton in the South China Sea. J Geophys Res 112:C02017. doi:10.1029/2006JC003536

Zhao H, Tang DL, Wang Y (2008) Comparison of phytoplankton blooms triggered by two typhoons with different intensities and translation speeds in the South China Sea. Mar Ecol Prog Ser 365:57-65

Zheng GM, Tang DL (2007) Offshore and nearshore chlorophyll increases induced by typhoon winds and subsequent terrestrial rainwater runoff. Mar Ecol Prog Ser 333:61-74

> Zheng ZW, Ho CR, Kuo NJ (2008) The importance of preexisting oceanic conditions to upper ocean response induced by Super Typhoon Hai-Tang. Geophys Res Lett 35:L20603. doi:10.1029/2008GL035524 
Appendix 1. Objective definition of typhoon forcing time

At first, we simply assume that the typhoon impact region is within the area where wind speed is over a critical value $U_{\text {c }}$ (e.g. $U_{\mathrm{c}}=17 \mathrm{~m} \mathrm{~s}^{-1}$ ) along its track. Secondly, for each point, the blowing time of the point is defined as the total time for which the wind speed is over $>U_{\mathrm{c}}$. Additionally, the max total blowing time is defined as the forcing time in this region. Numerical implementation would require that every $6 \mathrm{~h}$ track is interpolated as the short-time (e.g. half-hour) track. Fig. A1a shows the blowing time calculated by this method, where the contour curve labeled ' 40 ' means that the water within this region has a forcing time larger than $40 \mathrm{~h}$. The forcing time in this region is calculated at about $82 \mathrm{~h}$ with an error $<1 \mathrm{~h}$ (Fig. A1a).

We can also roughly estimate the forcing time by following the conclusion drawn by Hanshaw et al. (2008). It is simply assumed that the typhoon impact region is within the area where the distance between the point and typhoon track is less than $200 \mathrm{~km}$. Then, we draw a sample circle box with a diameter of $200 \mathrm{~km}$ and move this sample box to ensure that it completely covers the tracks (Fig. A1b). After summing the forcing times by accounting for the tracks in the box, the forcing time in this region was calculated as $\sim 102 \mathrm{~h}$ with an error $<3 \mathrm{~h}$ (half of the original typhoon track time interval).

Fig. A1c shows the forcing time using a variable radius in comparison with that using a fixed $200 \mathrm{~km}$ radius. As the typical forcing radius is about $150 \mathrm{~km}$ for a Category 1 typhoon, a fixed $200 \mathrm{~km}$ radius would lead to overestimation for weak typhoons like Hagibis (Fig A1b), while this fixed radius would lead to underestimation for strong typhoons.
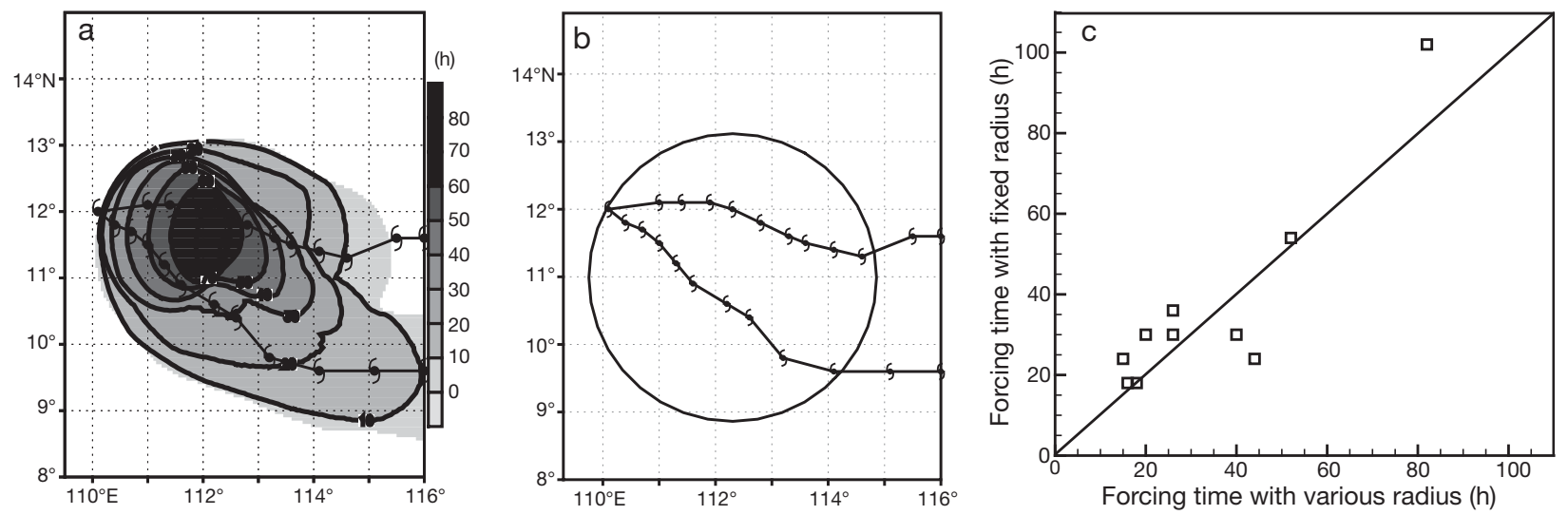

Fig. A1. (a) Blowing time along the track by a variable forcing radius at wind speeds $>15 \mathrm{~m} \mathrm{~s}^{-1}$, with a maximum blowing time (forcing time) of $\sim 82 \mathrm{~h}$. The contour curve labeled ' 40 ' indicates a long-term forcing region that has a forcing time of $>40 \mathrm{~h}$. (b) Forcing time $(\sim 102 \mathrm{~h})$ calculated by a moving circle sample box with a radius of $200 \mathrm{~km}$. (c) Forcing times calculated with variable radii versus those with a fixed radius of $200 \mathrm{~km}$ for all typhoons

Editorial responsibility: Katherine Richardson, Copenhagen, Denmark
Submitted: September 11, 2009; Accepted: December 22, 2009 Proofs received from author(s): April 1, 2010 